\title{
Plasmapheresis for acute attacks in neuromyelitis optica spectrum disorders
}

Neurol Neuroimmunol Neuroinflamm 2019;6:e518. doi:10.1212/NXI.0000000000000518

In the Editorial "Plasmapheresis for acute attacks in neuromyelitis optica spectrum disorders," the fourth reference incorrectly cites the article's authors as "Hartung HP, Ringelstein M, Geis C, et al.," but should read “Kleiter I, Gahlen A, Borisow N, et al.” The author regrets the error.

\section{Reference}

1. Levy M. Plasmapheresis for acute attacks in neuromyelitis optica spectrum disorders. Neurol Neuroimmunol Neuroinflamm 2018;5: e510. doi: 10.1212/NXI.0000000000000510. 


\section{Neurology \\ Neuroimmunology \& Neuroinflammation}

\section{Plasmapheresis for acute attacks in neuromyelitis optica spectrum disorders \\ Neurol Neuroimmunol Neuroinflamm 2019;6; \\ DOI 10.1212/NXI.0000000000000518}

This information is current as of November 7, 2018

Updated Information \&

Services

References

Permissions \& Licensing

Reprints including high resolution figures, can be found at:

http://nn.neurology.org/content/6/1/e518.full.html

This article cites 1 articles, 1 of which you can access for free at: http://nn.neurology.org/content/6/1/e518.full.html\#\#ref-list-1

Information about reproducing this article in parts (figures,tables) or in its entirety can be found online at:

http://nn.neurology.org/misc/about.xhtml\#permissions

Information about ordering reprints can be found online: http://nn.neurology.org/misc/addir.xhtml\#reprintsus

Neurol Neuroimmunol Neuroinflamm is an official journal of the American Academy of Neurology.

Published since April 2014, it is an open-access, online-only, continuous publication journal. Copyright $(\subseteq$ 2018 American Academy of Neurology. All rights reserved. Online ISSN: 2332-7812.

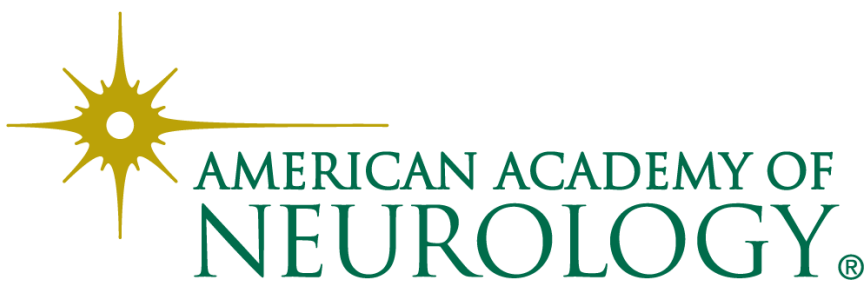

